\title{
A HPLC-UV Method for the Quantification of Phenolic Acids in Cereals
}

\author{
Mohammed E. Hefni ${ }^{1,2}$ (D) - Laura S. Amann ${ }^{1,3} \cdot$ Cornelia M. Witthöft $^{1}$ \\ Received: 18 April 2019 / Accepted: 27 August 2019 /Published online: 6 September 2019 \\ (C) The Author(s) 2019
}

\begin{abstract}
Cereals are a good source of phenolic acids, most of which are present in bound form. The aim of this study was to develop a method for quantifying total phenolic acids in cereals that includes a robust step for hydrolysis of bound forms. Different hydrolysis procedures were evaluated. Acid hydrolysis, even with subsequent use of enzymes, proved unsuitable for releasing bound phenolic acids from the cereal matrix. Base hydrolysis ( $3 \mathrm{M}, 90 \mathrm{~min}$ ) resulted in the highest extractability, with average recoveries of 88-108\% for cereal phenolic acids. The phenolic acid content in cereals (two cultivars each of rye, barley, and oats, and eight cultivars of wheat) varied up to 2-fold between cereal genotypes and 1.5-fold within genotypes. The highest content was found in rye, followed by wheat, barley, and oats. Ferulic acid dominated in all cereals, amounting to $48-72 \%$ of total phenolic acid content.
\end{abstract}

Keywords Phenolic acids $\cdot$ Extraction $\cdot$ Cereals $\cdot$ HPLC-UV

\section{Introduction}

A recent meta-analysis provided evidence that whole grain intake is associated with a reduced risk of cardiovascular disease and cancer (Aune et al. 2016). This has been attributed partly to the high content of phenolic compounds present in whole grain cereals (Dykes and Rooney 2007), which function as antioxidants (Slavin et al. 1997; Thompson 1994). The term phenolic acids refers to a large number of naturally occurring compounds in plant-derived foods which, based on $\mathrm{C} 1-\mathrm{C} 6$ and $\mathrm{C} 3-\mathrm{C} 6$ backbone, are divided into two main groups, benzoic acid and cinnamic acid derivatives. Several compounds are reported in each of these two groups. The structural dissimilarities derive from the number and position of the hydroxyl and methoxy groups on the aromatic ring.

A wide range of phenolic acid concentrations (197-3907 $\mu \mathrm{g} / \mathrm{g}$ ) in cereals has been reported, depending on genotype,

Mohammed E. Hefni

mohammed.hefni@lnu.se

1 Department of Chemistry and Biomedical Sciences, Faculty of Health and Life Sciences, Linnaeus University, 39231 Kalmar, Sweden

2 Food Industries Department, Faculty of Agriculture, Mansoura University, P.O. Box 46, Mansoura 35516, Egypt

3 Analytical Food Chemistry, Technische Universität München, Maximus-von-Imhof-Forum 2, 85354 Freising, Germany cultivar, growing conditions, and cereal fraction (Dykes and Rooney 2007). The majority (up to 90\%) of the phenolic acids in cereals are found in bound form (Acosta-Estrada et al. 2014; Robbins 2003; Shahidi and Yeo 2016). They are mainly ester-linked to cell wall components (Acosta-Estrada et al. 2014; Robbins 2003; Shahidi and Yeo 2016), which makes extraction difficult. Therefore, hydrolysis of the esters to carboxylic acid is considered an important prerequisite in any analytical method for determining bound phenolic acid content in cereal grains. There are two main procedures to cleave the ester bond for release of the phenolic acids from the food matrix, acid hydrolysis and base hydrolysis. A third, less prevalent, technique is cleavage using enzymes (esterases) (Acosta-Estrada et al. 2014; Robbins 2003; Shahidi and Yeo 2016). To the best of our knowledge, no previous study has systematically compared these different hydrolysis methods. Moreover, no definitive method for hydrolysis of bound phenolic acids in foods has been established to date and thus, there is a need to develop a simple method that quantitatively releases the phenolic acids from food matrices.

A number of methods have been developed for quantification of phenolic acids in foods, including the Folin-Ciocalteu assay and chromatographic approaches (HPLC-UV, GC-MS, LC-MS) (Acosta-Estrada et al. 2014; Robbins 2003; Shahidi and Yeo 2016). The Folin-Ciocalteu assay, which provides an estimate of total phenolic content by quantifying the antioxidant capacity, is not specific to phenolic groups and suffers from interference by ascorbic acid and reducing sugars (Stalikas 2007). Chromatographic methods have been widely 
used to separate and characterize individual phenolic acids (Stalikas 2007). However, the relative profile of phenolic acids differs depending on the food type (Manach et al. 2004). Therefore, there is a need for development of a chromatographic (HPLC) method that can separate and measure simultaneously the prominent phenolic acids in various foods in a single run. Accurate quantification of phenolic acid content in foods would enable selection of foods with a high content of these health-promoting compounds. The aims of this study were thus (1) to develop a simple and robust hydrolysis method for releasing the bound phenolics from cereals and (2) to use the method to quantify the content of phenolic acids in different cereal genotypes.

\section{Materials and Methods}

\section{Chemicals, Enzymes, and Standards}

All chemicals and phenolic acid standards (18 phenolic acids, as listed in Table 1) were purchased from Sigma-Aldrich (St. Louis, USA) except for acetonitrile, methanol, and sodium hydroxide, which were purchased from VWR International (Stockholm, Sweden). All reagents were of p.a. grade except acetonitrile and methanol, which were of HPLC grade. Water was purified using a Milli-Q water purification system (Merck, Darmstadt, Germany).
Standard stock solutions of phenolic acids $(100 \mu \mathrm{g} / \mathrm{mL}$ for ellagic acid, $1000 \mu \mathrm{g} / \mathrm{mL}$ for all other phenolic acids) were prepared in methanol under subdued light and stored under nitrogen atmosphere at $-80{ }^{\circ} \mathrm{C}$ for 4 months. A standard mixture of the 18 phenolic acids $(6 \mu \mathrm{g} / \mathrm{mL}$ of ellagic acid, $20 \mu \mathrm{g} / \mathrm{mL}$ of all other phenolic acids) was prepared in $40 \%$ aqueous methanol under subdued light and stored under nitrogen atmosphere at $-80^{\circ} \mathrm{C}$ for 1 month. This standard mixture was used for optimization of the chromatographic conditions.

Thermostable $\alpha$-amylase (from Bacillus amyloliquefaciens, $\geq 250$ units/g) and cellulase (from Aspergillus niger, 1.44 units/mg) were obtained from SigmaAldrich (St. Louis, USA). Protease (from Bacillus licheniformis, $25 \mathrm{mg} / \mathrm{mL}$ ) was purchased from Megazyme (Bray, Ireland). Suspensions of $\alpha$-amylase and protease were used without any additional preparation. Before extraction, a cellulase solution $(20 \mu \mathrm{g} / \mathrm{mL})$ was prepared by dissolving cellulase powder in $0.1 \mathrm{M}$ aqueous sodium acetate.

\section{Cereal Samples}

A total of 14 cereal grain samples from different genera and cultivars were tested. Grain from two cultivars each of rye (genus Secale), barley (genus Hordeum), and oats (genus Avena) and eight cultivars of wheat (genus Triticum), harvested during 2015 and 2016, was obtained from different mills and producers. Grain samples (250-500 g) were vacuum-
Table 1 Calibration parameters, limits of detection and quantification, detection wavelengths, and molecular masses of phenolic acid standards used in the current study

\begin{tabular}{llllllll}
\hline Phenolic acid & Slope & Intercept & $R^{2}$ & $\begin{array}{l}\text { LOD } \\
(\mu \mathrm{g} / \mathrm{mL})\end{array}$ & $\begin{array}{l}\text { LOQ } \\
(\mu \mathrm{g} / \mathrm{mL})\end{array}$ & $\begin{array}{l}\lambda \\
(\mathrm{nm})\end{array}$ & Mass \\
\hline Gallic acid & 59.4 & -31.9 & 0.9996 & 0.01 & 0.03 & 270 & 170.12 \\
2,3,4-Trihydroxybenzoic acid & 82.6 & -59.1 & 0.9992 & 0.02 & 0.06 & 270 & 170.12 \\
3,4-Dihydroxybenzaldehyde & 86.0 & -45.7 & 0.9996 & 0.01 & 0.03 & 275 & 138.12 \\
$p$-Hydroxybenzoic acid & 114.8 & -54.7 & 0.9997 & 0.01 & 0.04 & 260 & 138.12 \\
Gentisic acid & 37.3 & -21.6 & 0.9997 & 0.04 & 0.13 & 325 & 154.12 \\
Vanillic acid & 104.9 & -54.8 & 0.9996 & 0.02 & 0.08 & 270 & 168.15 \\
Caffeic acid & 131.4 & -70.8 & 0.9996 & 0.02 & 0.06 & 325 & 180.16 \\
Vanillin & 78.1 & -44.5 & 0.9997 & 0.03 & 0.10 & 278 & 152.15 \\
Syringic acid & 55.4 & -36.8 & 0.9995 & 0.04 & 0.13 & 278 & 198.17 \\
Chlorogenic acid & 78.4 & -54.5 & 0.9995 & 0.05 & 0.16 & 325 & 354.31 \\
Benzoic acid & 7.0 & -6.4 & 0.9993 & 0.26 & 0.86 & 275 & 122.12 \\
$p$-Coumaric acid + & 234.8 & -94.6 & 0.9998 & 0.02 & 0.08 & 310 & 164.15 \\
$\quad$ syringaldehyde & & & & & & & 182.17 \\
Ferulic acid & 125.1 & -71.8 & 0.9995 & 0.01 & 0.03 & 325 & 194.18 \\
Sinapic acid & 119.6 & -68.3 & 0.9996 & 0.01 & 0.04 & 325 & 224.21 \\
$o$-Coumaric acid & 168.5 & -87.8 & 0.9996 & 0.01 & 0.03 & 275 & 164.16 \\
Cinnamic acid & 172.7 & -31.9 & 0.9999 & 0.01 & 0.03 & 275 & 148.16 \\
\hline & & & & & & &
\end{tabular}

$R^{2}$ correlation coefficient, $L O D$ limit of detection, $L O Q$ limit of quantification, established by signal-to-noise $(1: 10)$ approach. It was difficult to generate an accurate calibration curve for ellagic acid in the standard mixture because of the poor stability 
packed in polyethylene bags and stored at $-20{ }^{\circ} \mathrm{C}$ until analysis. Before analysis, the grain was milled using an ultracentrifuge mill, with a $0.5-\mathrm{mm}$ ring sieve (ZM 200, Retsch, Hannover, Germany).

\section{Optimization of the Hydrolysis Procedure}

Milled Emmer wheat (Triticum dicoccum, cultivar (cv.) Västgötarna) was used for optimization of the hydrolysis procedure. Two main approaches were tested for hydrolysis of total phenolic acids (acid hydrolysis and base hydrolysis, with/without thermostable $\alpha$-amylase, cellulase, and protease), based on methods described by others (Fuentealba et al. 2017; Ross et al. 2009; Yu et al. 2001). Different conditions with respect to hydrochloric acid $(\mathrm{HCl})$ and sodium hydroxide $(\mathrm{NaOH})$ concentrations, incubation time, and use of enzymes during hydrolysis were tested, as outlined in Fig. 1. The need for antioxidants (EDTA and ascorbic acid) during hydrolysis, acidification after base hydrolysis (different hy-

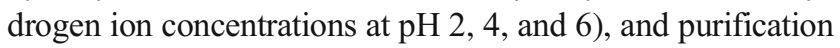
with dichloromethane was also examined (Fig. 1). After hydrolysis, sample extracts were filtered through a syringe filter $(0.45 \mu \mathrm{m}$ pore size, polypropylene membrane, Agilent Technologies, Santa Clara, USA). All hydrolysis procedures were performed in duplicate under nitrogen atmosphere and subdued light. The phenolic acid content of the extracts was measured under optimized chromatographic conditions using HPLC-UV. Phenolic acid content was quantified as the total of free, conjugated, and matrix-bound forms of the individual compound.

\section{Application of Optimized Procedure to Cereal Cultivars}

The optimized hydrolysis method for phenolic acid extraction from cereal samples was as follows: milled cereal grains $(0.2$ g) were homogenized $(n=3)$ in $0.8 \mathrm{~mL}$ aqueous ascorbic acid solution (12.5\%), $0.2 \mathrm{~mL}$ aqueous EDTA solution $(0.33 \mathrm{M})$, and $4 \mathrm{~mL} 3.75 \mathrm{M} \mathrm{NaOH}$ (to give a final concentration of $3 \mathrm{M}$ ). The mixture was shaken for $90 \mathrm{~min}$ at ambient temperature under nitrogen atmosphere protected from light. After base hydrolysis, the $\mathrm{pH}$ of the extract was adjusted to $\approx 6$ using
Fig. 1 Flow chart of different extraction procedures. Single asterisks mean extraction without enzyme: addition of ascorbic acid (AA) and EDTA, pH adjustment, and purification were also tested. Double asterisks mean incubation with individual enzymes was also tested
Base hydrolysis

Acid hydrolysis

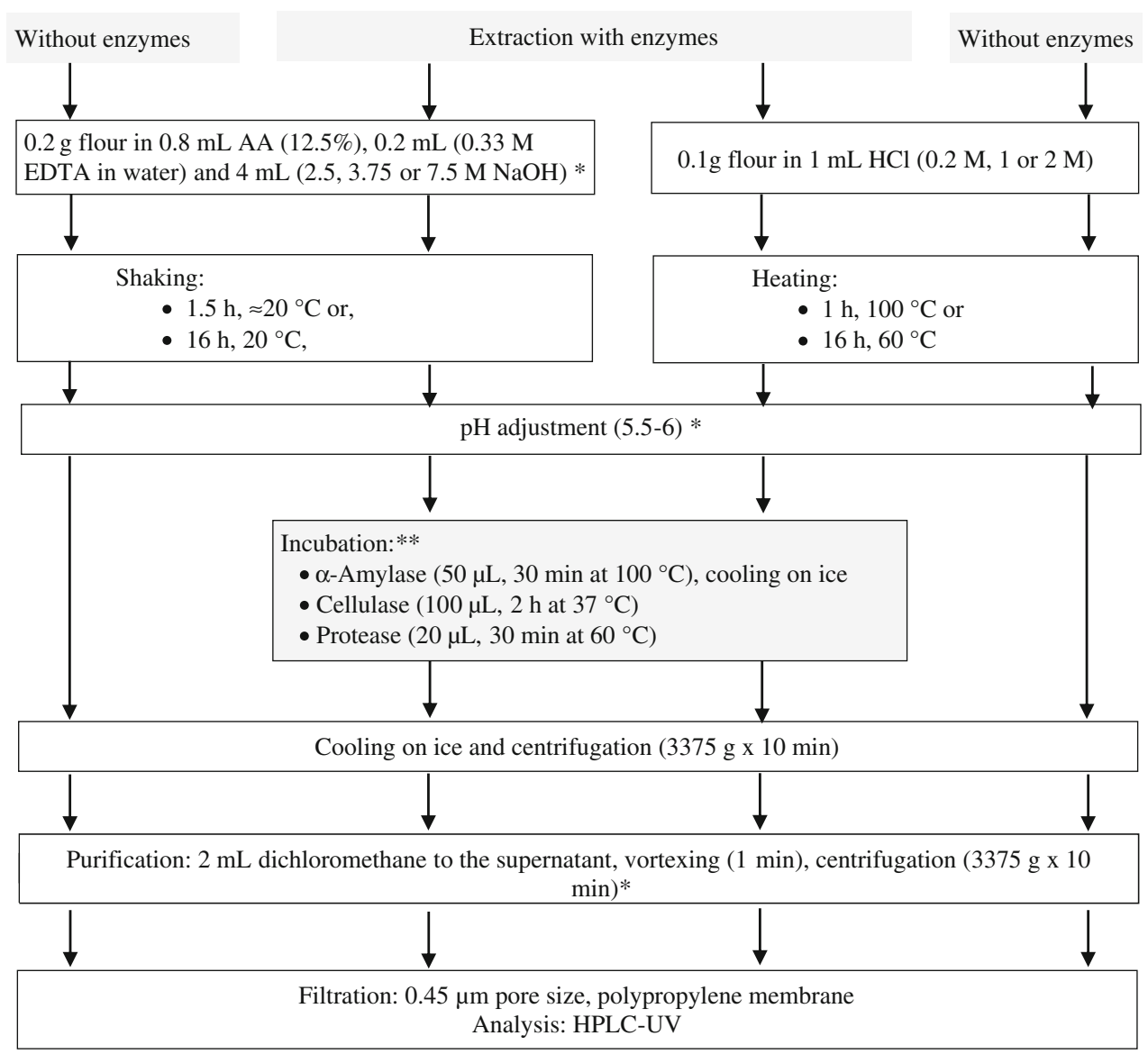


$\mathrm{HCl}(2 \mathrm{M})$. The mixture was vortexed for 1 min under nitrogen atmosphere and subdued light. After centrifugation (10 $\min , 3375 \mathrm{~g}$ ), an aliquot of the supernatant was filtered through a syringe filter $(0.45 \mu \mathrm{m}$ pore size $)$ and stored under nitrogen atmosphere at $-20^{\circ} \mathrm{C}$ until analysis within 1 week by HPLCUV using the optimized chromatographic conditions.

\section{Chromatographic Conditions}

Phenolic acids were quantified by HPLC with UV detection (Agilent 1260, Agilent Technologies, Santa Clara, USA). Phenolic acid compounds in standards and samples were separated on a reverse-phase C18 column (Luna, $250 \times 4.6 \mathrm{~mm}, 3 \mu \mathrm{m}, 100 \AA$; Phenomenex, Torrance, USA) with a guard column $(3.0 \times 4.0 \mathrm{~mm}$; Phenomenex, Torrance, USA) containing the same packing material. The column was thermostatically controlled at $25{ }^{\circ} \mathrm{C}$. The flow rate was set at $1.0 \mathrm{~mL} / \mathrm{min}$, the injection volume was $20 \mu \mathrm{L}$, and the total run time was $60 \mathrm{~min}$. On testing different gradient conditions and formic acid concentrations $(0.1 \%, 0.5 \%$, and $1 \%)$, it was found that nearly complete separation was achieved using the following mobile phase composition: solvent $\mathrm{A}$ ( $1 \%$ aqueous formic acid) and solvent $\mathrm{B}$ acetonitrile/methanol/water $(8: 1: 1, \mathrm{v} / \mathrm{v} / \mathrm{v})$. The gradient started at $6 \%$ solvent $\mathrm{B}$ and was maintained for 34 min, after which solvent B was increased to $23 \%$ within $1 \mathrm{~min}$. After $10 \mathrm{~min}$, solvent $\mathrm{B}$ was further increased to $50 \%$ within $1 \mathrm{~min}$ and held at 50\% for $4 \mathrm{~min}$. Solvent B was then decreased to $6 \%$ over $1 \mathrm{~min}$ and maintained there for a further $9 \mathrm{~min}$ to recondition the column before the next injection.

\section{Identification and Quantification of Phenolic Acids}

The detection wavelengths were set at 260 ( $p$-hydroxybenzoic acid, vanillic acid, ellagic acid), 270 (gallic acid, 2,3,4trihydroxybenzoic acid), 275 (3,4-dihydroxybenzaldehyde, vanillin, syringic acid, benzoic acid, $o$-coumaric acid, cinnamic acid), 310 ( $p$-coumaric acid, syringaldehyde), and $325 \mathrm{~nm}$ (gentisic acid, caffeic acid, chlorogenic acid, ferulic acid, sinapic acid) (Table 1). Aqueous calibration standard solutions were prepared by serial dilution to contain 0.001 , $0.005,0.01,0.05,0.1,0.5,1,2,5$, and $10 \mu \mathrm{g} / \mathrm{mL}$ ellagic acid and $0.01,0.05,0.1,0.5,1,5,10,20,50$, and $100 \mu \mathrm{g} / \mathrm{mL}$ of all other phenolic acids to determine the limit of detection (LOD) and limit of quantification (LOQ). The LOD and LOQ were estimated by the signal-to-noise $(S / N)$ ratio of 3 for LOD and 10 for LOQ for each compound.

Quantification was based on multilevel external calibration curves with a linear range over $0.03-100 \mu \mathrm{g} / \mathrm{mL}$ for gallic acid and 3,4-dihydroxybenzaldehyde; $0.04-100 \mu \mathrm{g} / \mathrm{mL}$ for $p$ hydroxybenzoic acid and sinapic acid; $0.06-100 \mu \mathrm{g} / \mathrm{mL}$ for caffeic acid and 2,3,4-trihydroxybenzoic acid; 0.08-100 $\mu \mathrm{g} /$ $\mathrm{mL}$ for vanillic acid and $p$-coumaric acid + syringaldehyde; $0.1-100 \mu \mathrm{g} / \mathrm{mL}$ for vanillin; $0.13-100 \mu \mathrm{g} / \mathrm{mL}$ for caffeic acid, gentisic acid, and syringic acid; $0.16-100 \mu \mathrm{g} / \mathrm{mL}$ for chlorogenic acid; and $0.86-100 \mu \mathrm{g} / \mathrm{mL}$ for benzoic acid.

\section{Quality Control of Analytical Methods}

To control for within- and between-day variation, an in-house control sample (Emmer, T. dicoccum, cv. Västgötarna), milled and stored in subsamples at $-20{ }^{\circ} \mathrm{C}$ under nitrogen atmosphere, was included in triplicate in each extraction batch $(n$ $=4)$. The coefficient of variation $(\mathrm{CV})$ for within- and between-day variation was calculated from the replicates.

Recovery tests were performed by standard addition of vanillic acid, caffeic acid, vanillin, syringic acid, $p$-coumaric acid, ferulic acid, and sinapic acid to the in-house control sample (Emmer, T. dicoccum, cv. Västgötarna (in triplicate)). Standard was added aiming at two concentrations of each phenolic acid: for ferulic acid, $300 \mu \mathrm{g} / \mathrm{g}$ dry matter (DM) and $600 \mu \mathrm{g} / \mathrm{g} \mathrm{DM}$; for sinapic acid, $100 \mu \mathrm{g} / \mathrm{g} \mathrm{DM}$ and 200 $\mu \mathrm{g} / \mathrm{g} \mathrm{DM}$; for all other compounds, $50 \mu \mathrm{g} / \mathrm{g}$ of DM and 100 $\mu \mathrm{g} / \mathrm{g}$ DM. The recovery $(R)$ was calculated as:

$\mathrm{R}(\%)=100 \times\left(\mathrm{C}_{\text {found }}-\mathrm{C}_{\text {sample }}\right) / \mathrm{C}_{\text {added }}$

where $\mathrm{C}_{\text {found }}$ is the measured content in the spiked sample, $\mathrm{C}_{\text {sample }}$ is the measured content in the sample before spiking, and $\mathrm{C}_{\text {added }}$ is the added concentration.

In order to check the stability of chlorogenic acid during base hydrolysis, $50 \mu \mathrm{L}$ of chlorogenic acid standard (1000 $\mu \mathrm{g} /$ $\mathrm{mL}$ in methanol) was treated $(n=2)$ as a sample according to the optimized procedure to cereal cultivars.

\section{Calculations and Statistics}

The values presented are mean $(\mu \mathrm{g} / \mathrm{g}$ dry matter $(\mathrm{DM})) \pm$ standard deviation (SD) of duplicate samples during method development, or of triplicate samples during recovery and analysis of cereal samples except for the in-house control sample Emmer (Västgötarna) which was included into every batch during analysis $(n=12)$. The sum of individual phenolic acids was expressed in $\mu \mathrm{g}$ ferulic acid/g DM, after conversion using the molecular mass values listed in Table 1. $p$-Coumaric acid and syringaldehyde coeluted and were expressed as $p$ coumaric acid, as only traces of syringaldehyde have been reported in cereals ( $\mathrm{Li}$ et al. 2008). One-way ANOVA and Tukey's pair-wise comparison, with the level of significance set at $P<0.05$, were used to analyze differences between hydrolysis methods, and between and within different cereal 
species. All statistical analyses were carried out using Minitab (Minitab Ltd, Coventry, UK).

\section{Results}

\section{Optimization of Chromatographic and Extraction Conditions}

Separation of phenolic acids is mainly performed on a C18 column (see review by Robbins (2003)). A standard C18 column with a $3 \mu \mathrm{m}$ particle size was chosen in the present work, to be consistent with the aim of developing a robust method. With the exception of $p$-coumaric acid, which coeluted with syringaldehyde acid, 16 phenolic acids were successfully separated (Fig. 2). Addition of formic acid to the mobile phase was required for both separation and peak shape, which improved with increasing formic acid concentration from 0.1 to $1 \%$ (Fig. 2).
Up to 5-fold higher extractability was observed after base hydrolysis compared with acid hydrolysis (Fig. 3), depending on the hydrolysis conditions. This indicates that base hydrolysis was more effective in releasing the esterified and conjugated phenolic acids. Incubation with enzymes, i.e., $\alpha$-amylase, protease, and cellulase, after acid hydrolysis improved the extractability by 4-fold, but was half as efficient as base hydrolysis (Fig. 3 (II and III)). On increasing the molarity of $\mathrm{HCl}$ from 0.2 to 1 or $2 \mathrm{M}$, the stability of compounds was negatively affected and extraction resulted in $48 \%$ and $72 \%$ lower phenolic acid content, respectively (Fig. 3 (III)).

The highest extractability of phenolic acids was achieved after base hydrolysis ( $3 \mathrm{M} \mathrm{NaOH}, 90 \mathrm{~min}$ ). Higher $(6 \mathrm{M})$ or lower $(2 \mathrm{M})$ base concentration did not affect the extractability (Fig. 3 (III)). Moreover, increasing the incubation time from 1.5 to $16 \mathrm{~h}$ and addition of hydrolyzing enzymes ( $\alpha$-amylase, protease, and cellulase) did not result in any significant increase in phenolic acids (Fig. 3 (I and II)). Enzymatic treatment was therefore

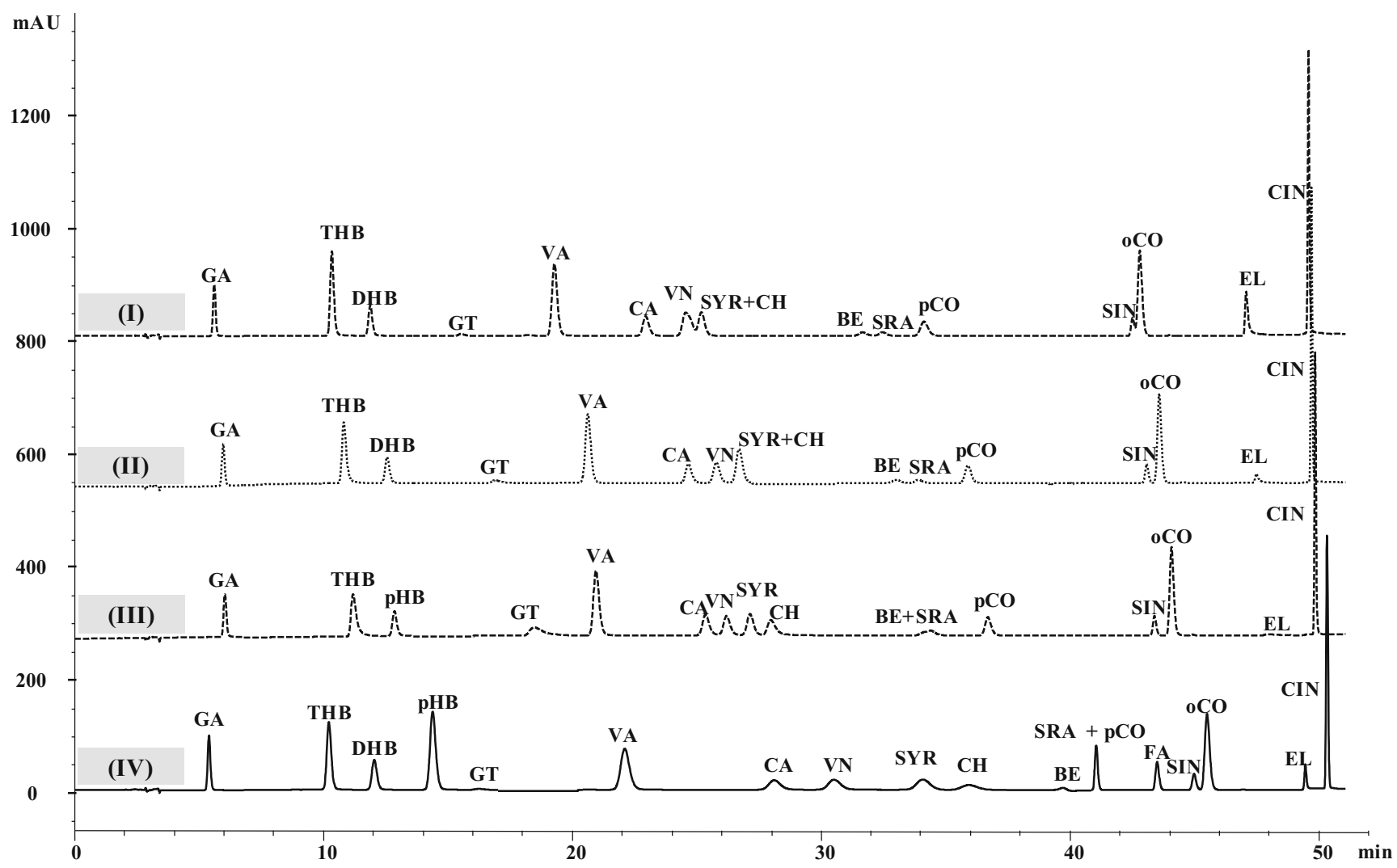

Fig. 2 Chromatograms of a standard mixture of 18 phenolic acids at $260 \mathrm{~nm}$ using different concentrations of formic acid in the mobile phase: (I) $0.1 \%$ formic acid, (II) $0.5 \%$ formic acid, (III, IV) $1 \%$ formic acid. Solvent A consists of different formic acid concentrations in water and solvent $\mathrm{B}$ of acetonitrile/methanol/water $(8: 1: 1, \mathrm{v} / \mathrm{v} / \mathrm{v})$. In I, II, and III, the gradient for solvent B started at $6 \%$ and was then increased to $12 \%$ over $30 \mathrm{~min}$, to $30 \%$ over $15 \mathrm{~min}$, and to $50 \%$ over $1 \mathrm{~min}$. It was held at $50 \%$ for $2 \mathrm{~min}$, and then lowered to $6 \%$ over $1 \mathrm{~min}$ and kept there for $6 \mathrm{~min}$ to recondition the column before the next injection. Total run time

was $55 \mathrm{~min}$. In panel IV, the optimized gradient conditions were used. GA gallic acid, THB 2,3,4-trihydroxybenzoic acid, DHB 3,4dihydroxybenzaldehyde, $p \mathrm{HB} p$-hydroxybenzoic acid, GT gentisic acid, VA vanillic acid, CA caffeic acid, VN vanillin, SYR syringic acid, $\mathrm{CH}$ chlorogenic acid, BE benzoic acid, SRA syringaldehyde, $p \mathrm{CO}$ $p$-coumaric acid, FA ferulic acid, SIN sinapic acid, $o \mathrm{CO} o$-coumaric acid, EL ellagic acid, CIN cinnamic acid. The concentration used was $6 \mu \mathrm{g} / \mathrm{mL}$ for EL and $20 \mu \mathrm{g} / \mathrm{mL}$ for all other phenolic acids 

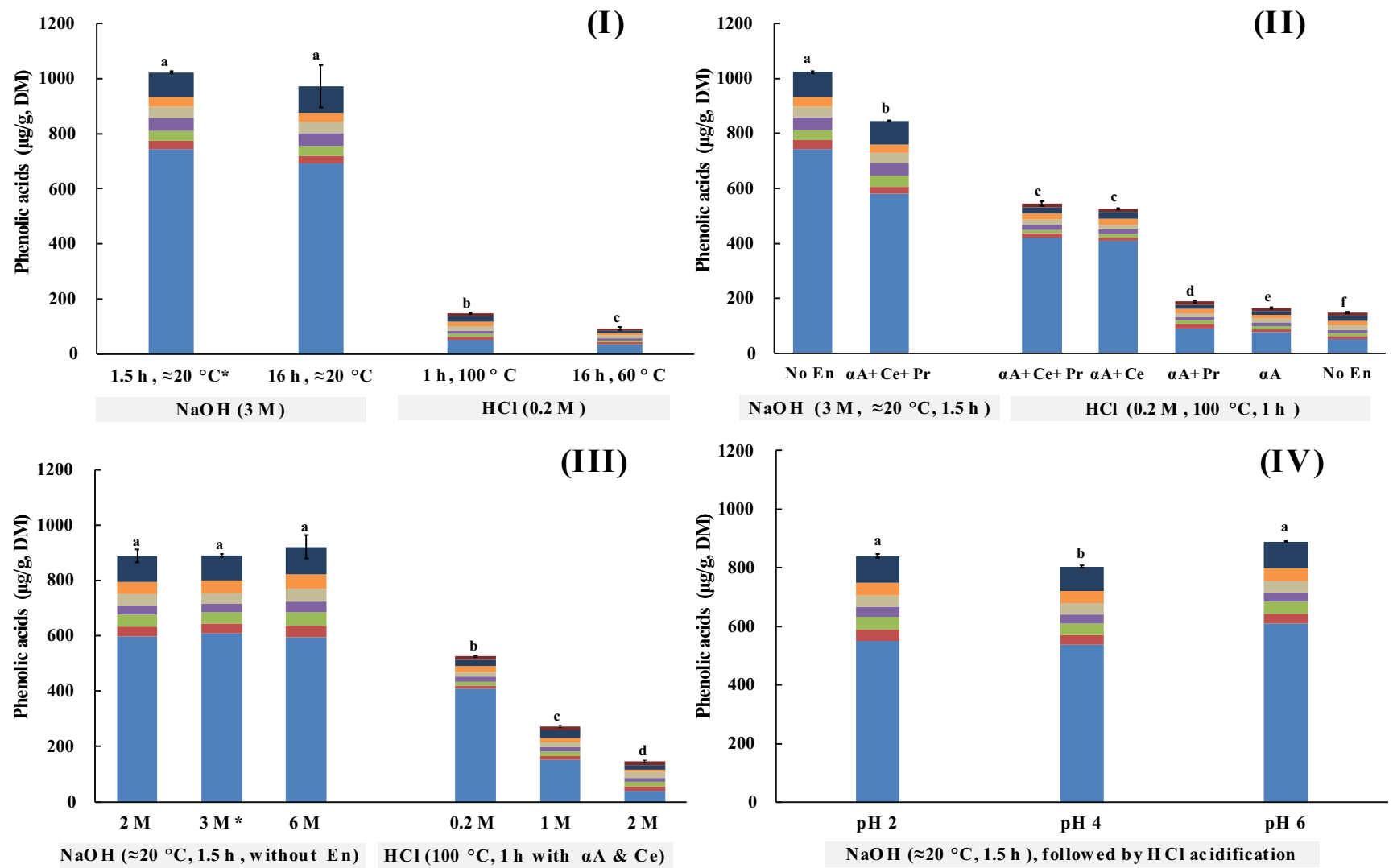

Fig. 3 Effect of different extraction procedures in terms of (I) extraction time, (II) use of enzymes, (III) acid or base concentration during hydrolysis, and (IV) acidification after base hydrolysis on the extractability of phenolic acids $(\mu \mathrm{g} / \mathrm{g}, \mathrm{DM})$ in whole grain wheat flour (Emmer, cv. Västgötarna). Columns represent means of duplicate samples $(n=2)$. Error bars were calculated for the sum of phenolic acids. Different superscripts represent significant differences $(P<0.05)$. Single asterisks mean

experiments summarized in each panel were partly carried out at different occasions; data are therefore underlying the day-to-day variation of $\leq$ $10 \%$. Ferulic acid, $\square$-hydroxybenzoic acid, vanillic acid, $\square$ caffeic acid, $\square$ syringic acid, $\square$-coumaric acid, $\square$ sinapic acid, $\square$ 3,4dihydroxybenzaldehyde. No En no enzymes, $\alpha$ A $\alpha$-amylase, Ce cellulase, $\operatorname{Pr}$ protease

omitted during hydrolysis, to simplify the extraction procedure and reduce costs. However, acidification to $\mathrm{pH}$ 5.5-6 after base hydrolysis was shown to be important, especially when quantifying syringic acid, as $\approx 15 \%$ of the content was lost if the $\mathrm{pH}$ was not adjusted. Decreasing the $\mathrm{pH}$ further to 4 or 2 after base hydrolysis did not significantly alter the measurable content (Fig. 3 (IV)), indicating that bound phenolic acids were fully hydrolyzed during base hydrolysis.

Caffeic acid was only determined in cereal samples after addition of EDTA and ascorbic acid to improve the stability during extraction. However, the sum of the individual phenolics expressed as ferulic acid was not significantly affected $(P=0.13)$ due to the low content of caffeic acid in the samples. Furthermore, purification of hydrolysates with dichloromethane or ethyl acetate (to eliminate impurities) did not affect the results (data not shown).

The stability of phenolic acids during base hydrolysis was checked by treating a standard mix of all phenolic acids $(n=18)$ as a sample. All individual phenolic acids

showed stability above $90 \%$ (data not shown) with the exception of ellagic acid and chlorogenic acid (which is completely converted to caffeic acid at alkaline $\mathrm{pH}$ ) (Fig. 4).

\section{Quality Control of the Analytical Method}

The calibration curves of all phenolic acids except ellagic acid were linear up to $100 \mu \mathrm{g} / \mathrm{mL}\left(R^{2} \geq 0.9992\right)$ (Table 1). It was impossible to generate an accurate calibration curve for ellagic acid in a standard mixture including the other 17 phenolic acid compounds, due to the low stability of ellagic acid. The within-day $(n=3)$ and between-day $(n=$ 12) $\mathrm{CV}$ for the control sample (Emmer, T. dicoccum, cv. Västgötarna) was $\leq 10 \%$ in both cases for each individual phenolic acid (Table 2). The relative recovery of individual phenolic acids after standard addition to the control sample at two concentrations ( $n=3$, triplicate samples at two addition levels) ranged from $88 \%$ (caffeic acid) to 108\% (sinapic acid) (Table 3). 
Fig. 4 Conversion of chlorogenic acid (dotted line chromatogram) into caffeic acid (solid line chromatogram) during the base hydrolysis

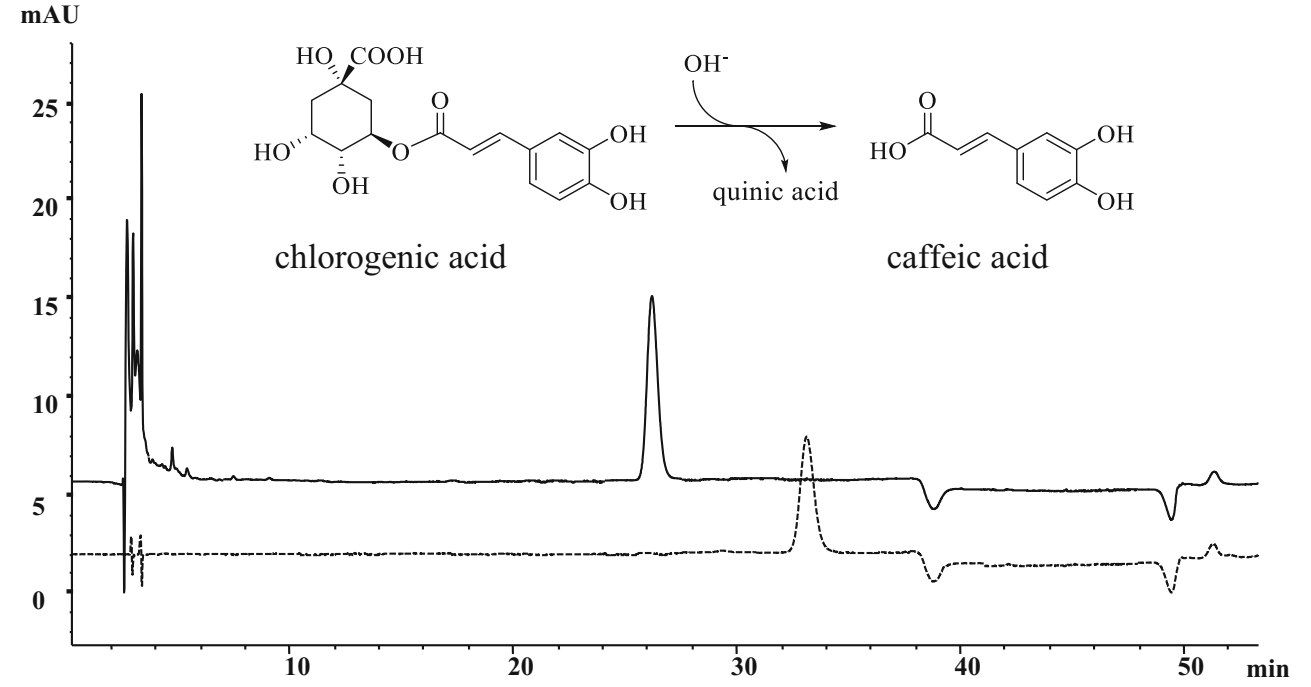

\section{Content of Phenolic Acids in Cereal Samples}

The phenolic acids $p$-hydroxybenzoic acid, vanillic acid, caffeic acid, vanillin, syringic acid, ferulic acid, sinapic acid, and $p$-coumaric acid/syringaldehyde were found in all cereals tested (Table 4). In addition to these, both rye cultivars contained 3,4-dihydroxybenzaldehyde. The sum of these compounds (Table 4) was expressed as ferulic acid ( $\mu \mathrm{g} / \mathrm{g}$, DM) due to differing molecular masses, as shown in Table 1. A typical chromatogram of a cereal sample (Emmer, T. dicoccum, cv. Västgötarna) after extraction using the optimized method is shown in Fig. 5. The average content of phenolic acids in the cereal samples varied significantly depending on cereal genus and species (Table 4). Rye contained the highest amounts, followed by wheat, barley, and oats, with concentrations ranging from $\approx 600 \mu \mathrm{g} / \mathrm{g}$ (barley) to $1150 \mu \mathrm{g} / \mathrm{g}$ (rye). The distribution of individual phenolic acids was similar in the different cereal samples (Table 4), with ferulic acid dominating (48-72\% of total phenolic acid content (Table 4)). Sinapic acid was the second most dominant form, representing up to $11 \%$ of total phenolic acid content (Table 4).

\section{Discussion}

Our aim was to develop a simple method for analysis of total phenolic acids in cereals, including free, bound, and conjugated forms, since the free forms only comprise $1-4 \%$ of the total content (Andersson et al. 2008; Li et al. 2008; Nyström et al. 2008; Shewry et al. 2008). Our results showed that base hydrolysis is more effective for extraction of phenolic acids from the cereal matrix than acid hydrolysis, with or without use of sequential enzyme hydrolysis. Base and acid hydrolysis have
Table 2 Precision of the quantification method for phenolic acids in the wheat inhouse control sample (Emmer, T. dicoccum, cv. Västgötarna)

\begin{tabular}{llll}
\hline Phenolic acid & $\begin{array}{l}\text { Mean content } \\
(\mu \mathrm{g} / \mathrm{g}, \mathrm{DM})\end{array}$ & $\begin{array}{l}\text { RSD }(\%), n=3, \\
\text { intra-assay }\end{array}$ & $\begin{array}{l}\text { RSD }(\%), n=12, \\
\text { inter-assay }\end{array}$ \\
\hline$p$-Hydroxybenzoic acid & $27 \pm 0.3$ & 0.27 & 1.1 \\
Vanillic acid & $33 \pm 0.7$ & 0.11 & 2.1 \\
Caffeic acid & $41 \pm 1.5$ & 1.59 & 3.6 \\
Vanillin & $32 \pm 0.8$ & 0.02 & 2.5 \\
Syringic acid & $37 \pm 0.4$ & 0.40 & 1.1 \\
$p$-Coumaric acid + syringaldehyde & $37 \pm 2.0$ & 2.75 & 5.5 \\
Ferulic acid & $591 \pm 59.8$ & 5.00 & 10.1 \\
Sinapic acid & $82 \pm 6.6$ & 2.94 & 8.1 \\
Total, expressed in ferulic acid* & $901 \pm 68.8$ & 3.74 & 7.6 \\
\hline
\end{tabular}

The following phenolic acids were not detected: gallic acid, 2,3,4-trihydroxybenzoic acid, 3,4dihydroxybenzaldehyde, gentisic acid, chlorogenic acid, benzoic acid, $o$-coumaric acid, ellagic acid, and cinnamic acid

*The sum of individual phenolic acids expressed in ferulic acid using the molecular masses listed in Table 1 $n$ refers to sample replicates, for intra-assay as triplicate on the same day, for inter-assay on 12 independent days 
Table 3 Recovery of phenolic acids during quantification in Emmer (T. dicoccum, cv.Västgötarna)

\begin{tabular}{|c|c|c|c|c|c|}
\hline Phenolic acid & $\begin{array}{l}C_{\text {sample }} \\
(\mu \mathrm{g} / \mathrm{g} D \mathrm{DM})\end{array}$ & $\begin{array}{l}C_{\text {added }} \\
(\mu \mathrm{g} / \mathrm{g} \mathrm{DM})\end{array}$ & $\begin{array}{l}C_{\text {found }} \\
(\mu \mathrm{g} / \mathrm{g} \mathrm{DM})\end{array}$ & Recovery (\%) & Mean recovery $(\%)$ \\
\hline Vanillic acid & $32 \pm 0.1$ & $\begin{array}{l}50 \\
100\end{array}$ & $\begin{array}{l}78 \pm 0.8 \\
126 \pm 0.8\end{array}$ & $\begin{array}{l}91 \\
94\end{array}$ & 93 \\
\hline Caffeic acid & $39 \pm 0.6$ & $\begin{array}{l}50 \\
100\end{array}$ & $\begin{array}{l}83 \pm 1.6 \\
127 \pm 1.7\end{array}$ & $\begin{array}{l}88 \\
88\end{array}$ & 88 \\
\hline Vanillin & $32 \pm 0.1$ & $\begin{array}{l}50 \\
100\end{array}$ & $\begin{array}{l}80 \pm 0.3 \\
132 \pm 1.6\end{array}$ & $\begin{array}{l}96 \\
100\end{array}$ & 98 \\
\hline Syringic acid & $37 \pm 0.1$ & $\begin{array}{l}50 \\
100\end{array}$ & $\begin{array}{l}88 \pm 0.8 \\
142 \pm 1.1\end{array}$ & $\begin{array}{l}102 \\
105\end{array}$ & 104 \\
\hline$p$-Coumaric acid & $36 \pm 1.0$ & $\begin{array}{l}50 \\
100\end{array}$ & $\begin{array}{l}81 \pm 1.6 \\
126 \pm 2.5\end{array}$ & $\begin{array}{l}90 \\
90\end{array}$ & $90^{\mathrm{a}}$ \\
\hline Ferulic acid & $518 \pm 25.9$ & $\begin{array}{l}300 \\
600\end{array}$ & $\begin{array}{l}802 \pm 14.3 \\
1053 \pm 15.8\end{array}$ & $\begin{array}{l}94 \\
89\end{array}$ & 92 \\
\hline Sinapic acid & $76 \pm 2.2$ & $\begin{array}{l}100 \\
200\end{array}$ & $\begin{array}{l}185 \pm 3.9 \\
292 \pm 5.1\end{array}$ & $\begin{array}{l}109 \\
108\end{array}$ & 108 \\
\hline
\end{tabular}

$C_{\text {found }}$ mean content in the spiked sample, $C_{\text {sample }}$ mean content in the sample without spiking, $C_{\text {added }}$ content added to the sample

${ }^{a}$ Recovery was calculated only for $p$-coumaric acid (not for syringaldehyde). Concentrations are means of triplicate samples ( \pm standard deviation) different effects on plant cell wall compounds (Acosta-Estrada et al. 2014). Base hydrolysis is reported primarily to break the ester bonds, while acid hydrolysis is reported to break glycosidic bonds, solubilizing sugars without affecting the ester bonds (Acosta-Estrada et al. 2014). The bound phenolic acids in cereal grain are mainly ester-linked to cell wall components such as hemicellulose (e.g., arabinoxylans), cellulose, lignin, and pectin (Acosta-Estrada et al. 2014; Rhodes et al. 2002).

Table 4 Phenolic acid content ( $\mu \mathrm{g} / \mathrm{g}, \mathrm{DM})$ in cultivars of rye (Secale), wheat (Triticum), barley (Hordeum), and oats (Avena)

\begin{tabular}{|c|c|c|c|c|c|c|c|c|c|c|}
\hline \multirow[t]{2}{*}{ Cereal } & \multirow[t]{2}{*}{ Cultivar (origin) } & \multicolumn{9}{|c|}{ Phenolic acid content $(\mu \mathrm{g} / \mathrm{g}, \mathrm{DM})$} \\
\hline & & $p \mathrm{HB}$ & VA & $\mathrm{CA}$ & $\mathrm{VN}$ & SYR & $p \mathrm{CO}$ & FA & SIN & $\begin{array}{l}* * \text { Sum as } \\
\text { ferulic acid }\end{array}$ \\
\hline \multirow[t]{2}{*}{ Rye* } & Schmidt rye (Västgötarna) & $26 \pm 0.1$ & $28 \pm 0.4$ & $49 \pm 0.5$ & $35 \pm 1.0$ & $33 \pm 0.6$ & $48 \pm 1.2$ & $762 \pm 34.0$ & $104 \pm 2.0$ & $1148 \pm 41.6^{\mathrm{A}}$ \\
\hline & Rye (Saltå mill) & $26 \pm 0.4$ & $27 \pm 0.2$ & $45 \pm 1.2$ & $37 \pm 1.5$ & $33 \pm 0.4$ & $52 \pm 1.2$ & $696 \pm 30.3$ & $120 \pm 4.6$ & $1096 \pm 47.8^{\mathrm{AB}}$ \\
\hline \multirow[t]{8}{*}{ Wheat } & Spelt (Warbro mill) & $27 \pm 0.2$ & $31 \pm 0.4$ & $38 \pm 0.6$ & $30 \pm 0.6$ & $37 \pm 0.1$ & $30 \pm 0.3$ & $592 \pm 17.7$ & $61 \pm 1.2$ & $869 \pm 23.6^{\mathrm{F}}$ \\
\hline & Spelt (Saltå mill) & $26 \pm 0.2$ & $31 \pm 0.3$ & $41 \pm 1.1$ & $30 \pm 0.1$ & $38 \pm 0.4$ & $31 \pm 0.6$ & $703 \pm 43.2$ & $69 \pm 2.6$ & $991 \pm 58.0^{\mathrm{BCD}}$ \\
\hline & Öland spring wheat (Isgärde farm) & $27 \pm 0.1$ & $31 \pm 0.1$ & $38 \pm 0.2$ & $31 \pm 0.1$ & $36 \pm 0.1$ & $41 \pm 0.3$ & $590 \pm 9.0$ & $72 \pm 1.3$ & $891 \pm 12.8^{\mathrm{EF}}$ \\
\hline & Wheat (Saltå mill) & $26 \pm 0.1$ & $29 \pm 0.4$ & $36 \pm 0.4$ & $29 \pm 0.2$ & $36 \pm 0.2$ & $35 \pm 0.5$ & $639 \pm 19.8$ & $69 \pm 1.5$ & $923 \pm 26.0^{\mathrm{DEF}}$ \\
\hline & Jacoby Borst lantvete (Nibble farm) & $29 \pm 0.1$ & $36 \pm 0.1$ & $40 \pm 0.8$ & $31 \pm 0.1$ & $41 \pm 0.4$ & $47 \pm 1.9$ & $695 \pm 53.2$ & $80 \pm 3.0$ & $1025 \pm 72.7^{\mathrm{BCD}}$ \\
\hline & Wheat Dala lantvete (Västgötarna) & $27 \pm 0.1$ & $32 \pm 0.1$ & $38 \pm 0.1$ & $32 \pm 0.6$ & $38 \pm 0.2$ & $33 \pm 0.1$ & $770 \pm 17.3$ & $72 \pm 0.5$ & $1065 \pm 19.7^{\mathrm{ABC}}$ \\
\hline & Emmer (Västgötarna) & $27 \pm 0.3$ & $33 \pm 0.7$ & $41 \pm 1.5$ & $32 \pm 0.8$ & $37 \pm 0.4$ & $37 \pm 2.0$ & $591 \pm 59.8$ & $82 \pm 6.6$ & $901 \pm 68.8^{\mathrm{EF}}$ \\
\hline & Emmer (Warbro mill) & $27 \pm 0.1$ & $33 \pm 0.2$ & $40 \pm 0.1$ & $30 \pm 0.1$ & $37 \pm 0.4$ & $39 \pm 0.6$ & $596 \pm 6.4$ & $90 \pm 0.6$ & $915 \pm 8.3^{\mathrm{DEF}}$ \\
\hline \multirow[t]{2}{*}{ Barley } & Naked barley (Warbro mill) & $25 \pm 0.1$ & $34 \pm 0.1$ & $64 \pm 0.5$ & $31 \pm 0.3$ & $35 \pm 0.3$ & $29 \pm 0.1$ & $682 \pm 8.1$ & $42 \pm 0.4$ & $971 \pm 9.6^{\mathrm{CDEF}}$ \\
\hline & Barley (Saltå mill) & $24 \pm 0.1$ & $30 \pm 0.1$ & $41 \pm 0.5$ & $29 \pm 0.2$ & $33 \pm 0.2$ & $45 \pm 1.0$ & $340 \pm 9.4$ & $36 \pm 0.2$ & $607 \pm 12.8^{\mathrm{G}}$ \\
\hline \multirow[t]{2}{*}{ Oat } & Naked oat (Warbro mill) & $29 \pm 0.5$ & $32 \pm 0.7$ & $57 \pm 3.9$ & $30 \pm 0.3$ & $49 \pm 2.4$ & $30 \pm 0.6$ & $283 \pm 30.5$ & $61 \pm 4.6$ & $597 \pm 53.4^{\mathrm{G}}$ \\
\hline & Oat (Saltå mill) & $30 \pm 0.1$ & $32 \pm 0.3$ & $54 \pm 0.8$ & $32 \pm 0.6$ & $49 \pm 0.4$ & $27 \pm 0.2$ & $293 \pm 9.6$ & $73 \pm 0.8$ & $614 \pm 13.4^{\mathrm{G}}$ \\
\hline
\end{tabular}

*3,4-Dihydroxybenzaldehyde (DHB) only detected in rye samples: $29 \pm 0.4 \mu \mathrm{g} / \mathrm{g}$ in Västgötarna and $28 \pm 0.3 \mu \mathrm{g} / \mathrm{g}$ in Saltå mill

**The sum of individual phenolic acids, expressed as ferulic acid, using the molecular masses listed in Table 1. $p$ HB $p$-hydroxybenzoic acid, VA vanillic acid, $C A$ caffeic acid, $V N$ vanillin, $S Y R$ syringic acid, $p C O^{a} p$-coumaric acid (may also contain syringaldehyde), $F A$ ferulic acid, $S I N$ sinapic acid Individual phenolic acids are expressed as mean \pm standard deviation $(n=3$ for all cereal samples except for the in-house control sample Emmer (Västgötarna) with $n=12$ which was included into every batch during analysis)

Means with different letters are significantly different $(P<0.05)$ 


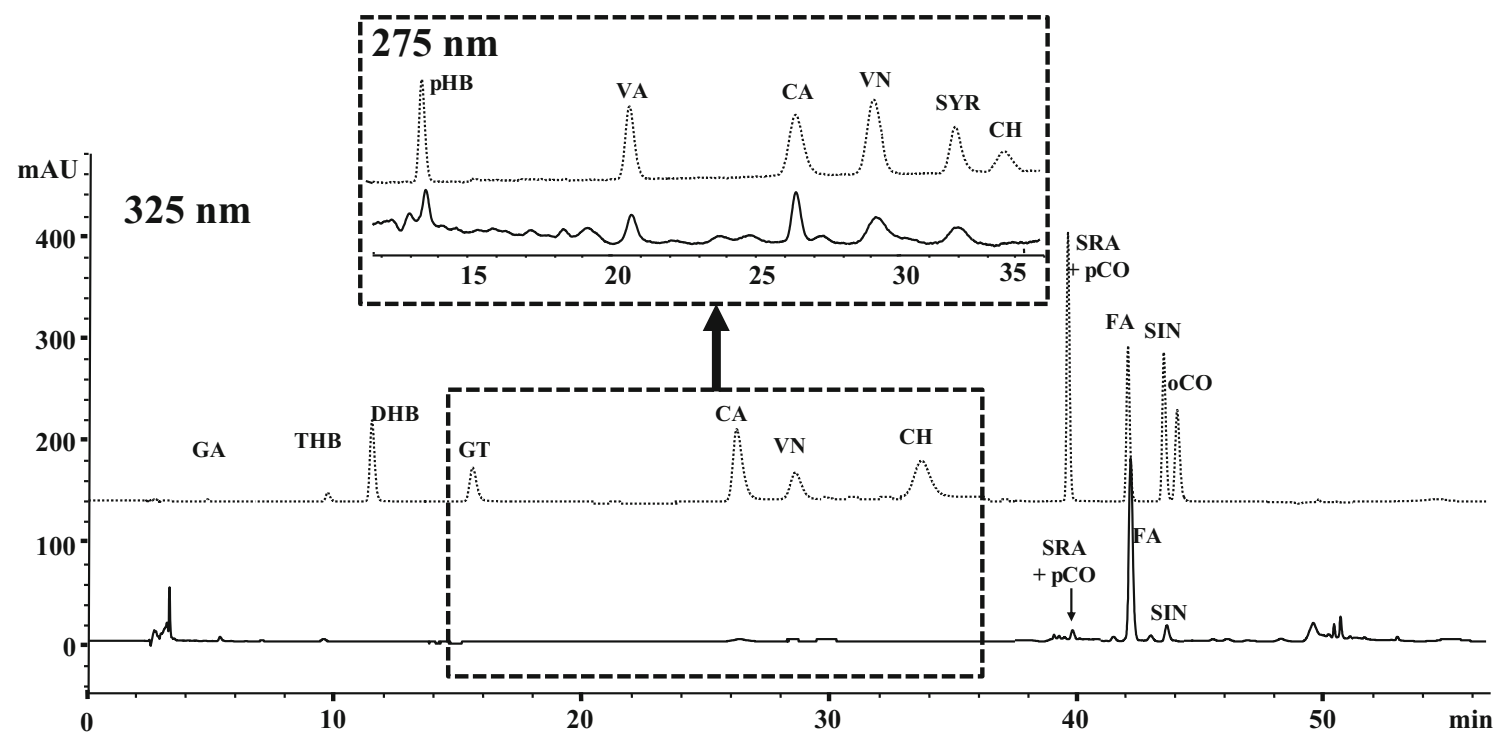

Fig. 5 Chromatograms of the in-house control sample Emmer (T. dicoccum, cv. Västgötarna) (solid line) after extraction using the optimized procedure and of the standard mixture of 18 phenolic acids (dotted line, $20 \mu \mathrm{g} / \mathrm{mL}$ except ellagic acid with $6 \mu \mathrm{g} / \mathrm{mL}$ ). Different wavelengths used in identification are listed in Table 1. GA gallic acid, THB 2,3,4-

For example, the hydroxycinnamic acids (e.g., ferulic acid, the major phenolic acid in cereals) are largely ester-linked to arabinose molecules in the arabinoxylan chain in cereal cell walls (Rhodes et al. 2002). This explains the ineffectiveness of acid hydrolysis for release of bound phenolic acids, as it leaves ester bonds intact (Fazary and Ju 2007). Increasing the acid concentration from 0.2 to 1 or $2 \mathrm{M}$ was found to negatively affect the stability of the phenolic acids and therefore decreased the measurable content, with losses being higher after treatment with $2 \mathrm{M}$ acid compared with $1 \mathrm{M}$. This confirmed the lower stability of phenolic acids under strong acidic conditions reported by others (Krygier et al. 1982; Verma et al. 2009). Combined acid and enzymatic hydrolysis with amylase, protease, and cellulase increased the extractability of phenolic acids to some extent, confirming findings by others (Yu et al. 2001). Nonetheless, the yield was still up to $50 \%$ lower than after base hydrolysis. To effectively release bound phenolic acids, specific esterases have to be used (Fazary and Ju 2007; Shahidi and Yeo 2016). This might explain the lower extractability observed in this study and others on using amylase, protease, and cellulase.

The highest extractability of phenolic acids was achieved after base hydrolysis (3 M, $90 \mathrm{~min}$ ). An increase in the base concentration or in the incubation time did not result in higher extractability. Ross et al. (2009) reported higher extractability after extraction using $10 \mathrm{~N} \mathrm{NaOH}$ compared with mild base hydrolysis using $2 \mathrm{~N} \mathrm{NaOH}$. In their study, the $10 \mathrm{~N} \mathrm{NaOH}(5$ $\mathrm{mL}$ ) was diluted with $10 \mathrm{~mL}$ water before extraction and therefore, the final concentration was $3.3 \mathrm{~N} \mathrm{NaOH}$, which is similar to that used in the present study. No significant changes in the content of phenolic acids were detected on using trihydroxybenzoic acid, DHB 3,4-dihydroxybenzaldehyde, $p \mathrm{HB}$ p-hydroxybenzoic acid, GT gentisic acid, VA vanillic acid, CA caffeic acid, VN vanillin, SYR syringic acid, $\mathrm{CH}$ chlorogenic acid, SRA syringaldehyde, $p \mathrm{CO} p$-coumaric acid, FA ferulic acid, SIN sinapic acid, $o \mathrm{CO}$ o-coumaric acid

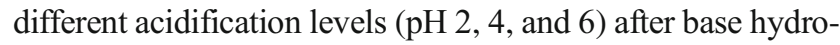
lysis (see Fig. 3 (IV)). This may confirm that the hydrolysis was caused by the alkali and not the acid.

Addition of ascorbic acid and EDTA to prevent losses of phenolic acids during base hydrolysis resulted only in improved stability of caffeic acid and did not significantly $(P=0.13)$ affect the sum of phenolic acids expressed as ferulic acid. Other studies have reported high stability of phenolic acids on using ascorbic acid and EDTA during extraction (Nardini et al. 2002; Ross et al. 2009). Under alkaline conditions, complete hydrolysis of chlorogenic acid to caffeic acid was observed (Fig. 5), by breaking the ester bond between caffeic and quinic acid, confirming findings by others (Nardini et al. 2002).

A limitation of this study was the co-elution of $p$-coumaric acid and syringaldehyde and the poor calibration curve for ellagic acid. However, these phenolic acids have not previously been detected in cereals, so this limitation is not expected to affect the measured phenolic acid content in cereals.

The high content of phenolic acids in cereal foods, in addition to their high consumption rate, makes them a significant source of phenolic acids in the European diet. Hence, information regarding the effects of genotype and species on the content of phenolic acids can be helpful in efforts to improve dietary intake. The results in this study confirmed that cereals are a rich source of phenolic acids (concentration range 600 to $>1000 \mu \mathrm{g} / \mathrm{g}$ ), although the concentration of phenolic acids quantified varied significantly between cereal genotypes (up to 2 -fold variation) and within the same genotype (1.5-fold variation). However, these data should be regarded as indicative rather than definitive, since only a few cereals were analyzed. Variation due to genotype and growing conditions in 
the concentration of phenolic acid in wheat $(422-1257 \mu \mathrm{g} / \mathrm{g}$, DM), rye (1093-1357 $\mu \mathrm{g} / \mathrm{g}$, DM), barley $(969-1132 \mu \mathrm{g} / \mathrm{g}$, $\mathrm{DM})$, and oats (351-874 $\mu \mathrm{g} / \mathrm{g}, \mathrm{DM})$ has been reported previously (Andersson et al. 2008, 2000; Fernandez-Orozco et al. 2010; Gawlik-Dziki et al. 2012; Li et al. 2008; Ndolo and Beta 2014; Nyström et al. 2008; Shewry et al. 2008).

The distribution of individual phenolic acids was similar in the different cereal samples tested (Table 4), with ferulic acid being the dominant form, followed by sinapic acid. The other phenolic acids ( $p$-coumaric acid, $p$-hydroxybenzoic acid, vanillic acid, caffeic acid, vanillin, and syringic acid) were only found in minor amounts. Similar distributions have been reported by others (Andersson et al. 2008, 2000; Fernandez-Orozco et al. 2010; Gawlik-Dziki et al. 2012; Li et al. 2008; Ndolo and Beta 2014; Nyström et al. 2008; Shewry et al. 2008). The compound 3,4-dihydroxybenzaldehyde was only detected in the two rye cultivars.

To summarize, a robust HPLC method was developed for simultaneous quantification of 16 individual phenolic acids deriving from free, conjugated, and bound forms in cereals. The method involves a short, cost-efficient hydrolysis step (no enzymes required). Acid hydrolysis, even followed by enzyme treatment, proved ineffective. The method was successfully applied in quantifying phenolic acids in different cereal genotypes and species. The results confirm that cereals are a good source of phenolic acids, but that the content is highly variable depending on cereal genotype and species.

\section{Conclusions}

A HPLC-UV method suitable for quantifying and identifying simultaneously 16 phenolic acids was developed. Up to nine phenolic acids were quantified in the tested cereal matrices at reduced cost and sample preparation time. Among the cereals, rye was the best source of phenolic acids. However, since only a few cultivars were analyzed, the findings should be regarded as indicative rather than definitive.

Funding Information Open access funding provided by Linnaeus University.

\section{Compliance with Ethical Standards}

Conflict of Interest Mohammed E. Hefni declares that he has no conflict of interest. Laura S. Amann declares that she has no conflict of interest. Cornelia M. Witthöft declares that she has no conflict of interest.

Ethical Approval This study does not contain any studies with human or animal subjects.

Informed Consent Not applicable
Open Access This article is distributed under the terms of the Creative Commons Attribution 4.0 International License (http:// creativecommons.org/licenses/by/4.0/), which permits unrestricted use, distribution, and reproduction in any medium, provided you give appropriate credit to the original author(s) and the source, provide a link to the Creative Commons license, and indicate if changes were made.

\section{References}

Acosta-Estrada BA, Gutiérrez-Uribe JA, Serna-Saldívar SO (2014) Bound phenolics in foods, a review. Food Chem 152:46-55. https://doi.org/10.1016/j.foodchem.2013.11.093

Andersson AAM, Lampi AM, Nyström L, Piironen V, Li L, Ward JL, Gebruers K, Courtin CM, Delcour JA, Boros D, Fraś A, Dynkowska W, Rakszegi M, Bedő Z, Shewry PR, Åman P (2008) Phytochemical and dietary fiber components in barley varieties in the HEALTHGRAIN diversity screen. J Agric Food Chem 56: 9767-9776. https://doi.org/10.1021/jf802037f

Andreasen MF, Christensen LP, Meyer AS, Hansen A (2000) Content of phenolic acids and ferulic acid dehydrodimers in 17 rye (Secale $\mathrm{c}$ ereale L.) varieties. J Agric Food Chem 48:2837-2842

Aune D, Keum NN, Giovannucci E, Fadnes LT, Boffetta P, Greenwood DC, Tonstad S, Vatten LJ, Riboli E, Norat T (2016) Whole grain consumption and risk of cardiovascular disease, cancer, and all cause and cause specific mortality: systematic review and dose-response meta-analysis of prospective studies. BMJ (Clinical research ed) 353:i2716-i2716. https:// doi.org/10.1136/bmj.i2716

Dykes L, Rooney LW (2007) Phenolic compounds in cereal grains and their health benefits. Cereal Foods World 52:105-111. https://doi. org/10.1094/CFW-52-3-0105

Fazary AE, Ju YH (2007) Feruloyl esterases as biotechnological tools: current and future perspectives. Acta Biochim Biophys Sin 39:811828. https://doi.org/10.1111/j.1745-7270.2007.00348.x

Fernandez-Orozco R, Li L, Harflett C, Shewry PR, Ward JL (2010) Effects of environment and genotype on phenolic acids in wheat in the HEALTHGRAIN diversity screen. J Agric Food Chem 58: 9341-9352

Fuentealba C, Quesille-Villalobos AM, González-Muñoz A, Saavedra Torrico J, Shetty K, Gálvez Ranilla L (2017) Optimized methodology for the extraction of free and bound phenolic acids from Chilean Cristalino corn (Zea mays L.) accession CyTA. J Food 15:91-98

Gawlik-Dziki U, Świeca M, Dziki D (2012) Comparison of phenolic acids profile and antioxidant potential of six varieties of spelt (Triticum spelta L.). J Agric Food Chem 60:4603-4612

Krygier K, Sosulski F, Hogge L (1982) Free, esterified, and insolublebound phenolic acids. 1. Extraction and purification procedure. $\mathrm{J}$ Agric Food Chem 30:330-334

Li L, Shewry PR, Ward JL (2008) Phenolic acids in wheat varieties in the HEALTHGRAIN diversity screen. J Agric Food Chem 56:97329739

Manach C, Scalbert A, Morand C, Remesy C, Jimenez L (2004) Polyphenols: food sources and bioavailability. Am J Clin Nutr 79: 727-747. https://doi.org/10.1093/ajcn/79.5.727

Nardini M, Cirillo E, Natella F, Mencarelli D, Comisso A, Scaccini C (2002) Detection of bound phenolic acids: prevention by ascorbic acid and ethylenediaminetetraacetic acid of degradation of phenolic acids during alkaline hydrolysis. Food Chem 79:119-124

Ndolo VU, Beta T (2014) Comparative studies on composition and distribution of phenolic acids in cereal grain botanical fractions. Cereal Chem 91:522-530. https://doi.org/10.1094/CCHEM-10-13-0225-R

Nyström L et al (2008) Phytochemicals and dietary fiber components in rye varieties in the HEALTHGRAIN diversity screen. J Agric Food Chem 56:9758-9766. https://doi.org/10.1021/jf801065r 
Rhodes DI, Sadek M, Stone BA (2002) Hydroxycinnamic acids in walls of wheat aleurone cells. J Cereal Sci 36:67-81. https://doi.org/10. 1006/jcrs.2001.0449

Robbins RJ (2003) Phenolic acids in foods: an overview of analytical methodology. J Agric Food Chem 51:2866-2887

Ross K, Beta T, Arntfield S (2009) A comparative study on the phenolic acids identified and quantified in dry beans using HPLC as affected by different extraction and hydrolysis methods. Food Chem 113: 336-344

Shahidi F, Yeo JD (2016) Insoluble-bound phenolics in food. molecules 21. https://doi.org/10.3390/molecules21091216

Shewry PR, Piironen V, Lampi AM, Nyström L, Li L, Rakszegi M, Fraś A, Boros D, Gebruers K, Courtin CM, Delcour JA, Andersson AAM, Dimberg L, Bedő Z, Ward JL (2008) Phytochemical and fiber components in oat varieties in the HEALTHGRAIN diversity screen. J Agric Food Chem 56:9777-9784. https://doi.org/10.1021/ jf801880d

Slavin J, Jacobs D, Marquart L (1997) Whole-grain consumption and chronic disease: protective mechanisms. Nutr Cancer 27:14-21
Stalikas CD (2007) Extraction, separation, and detection methods for phenolic acids and flavonoids. J Sep Sci 30:3268-3295. https:// doi.org/10.1002/jssc.200700261

Thompson LU (1994) Antioxidants and hormone-mediated health benefits of whole grains. Crit Rev Food Sci Nutr 34:473-497

Verma B, Hucl P, Chibbar RN (2009) Phenolic acid composition and antioxidant capacity of acid and alkali hydrolysed wheat bran fractions. Food Chem 116:947-954. https://doi.org/10.1016/j. foodchem.2009.03.060

Yu J, Vasanthan T, Temelli F (2001) Analysis of phenolic acids in barley by high-performance liquid chromatography. J Agric Food Chem 49:4352-4358

Publisher's Note Springer Nature remains neutral with regard to jurisdictional claims in published maps and institutional affiliations. 